\title{
THE RURAL-URBAN INTERFACE, A TERRITORIAL APPROACH TO THE SPATIAL FRAGMENTATION OF URBAN SPRAWL
}

\author{
Javier Delgado, Gabriela Angeles ${ }^{1}$ \\ Circuito Exterior s/n Ciudad Universitaria, Mexico, D. F. CP 04510, Mexico \\ e-mail: jdelgado@igiris.igeograf.unam.mx \\ e-mail: ganserr@servidor.unam.mx
}

\begin{abstract}
In the article influences of the urbanisation of outskirts of big cities in Mexico on natural environment as a whole and on individual elements thereof are analysed, in view of degradation as well as development factors. The so-called contact zone is hereby pointed out, including all its urbanisation changes. Conclusions are based on a qualitative evaluation and the so-called contact-spatial reclassification.
\end{abstract}

Key words: Mexico, urbanisation, peri-urban space, ecology, agglomeration, central region.

\section{INTRODUCTION}

Regional urbanization trends at the peri-urban space of large metropolis -just like Mexico City- are the cause of some impacts on natural resources and on ecological value areas that, unlike those generated by great agglomerations, are barely known.

Urban sprawl -unlike concentrated urbanization of fordist period, reaches great number of small and rural cities in big extensions, whereas its effects appear equally fragmented and dispersed. Only when it is analyzed as a whole, their real magnitude appears; however, the interest is mostly centered on big agglomerations and on intermediate cities, leaving neglected what happens on these small rural towns.

At the present time, neither general theory nor accepted paradigms about societies behavior on changing biosphere exists (Kates, et at, 1990:5). In addition, we face a frequent theoretical and methodological separation between "environmental" and "social" focuses in the disciplines related to environment (Head, 2000:3). While in social disciplines countrytown opposition model prevails, which leads to distinguish both words as separated fields -

1 This paper has been made with the collaboration of C. Galindo, M. Ricardez, M. Tautiva and J. Hernandez, to whom the authors are truly grateful. 
even for knowledge- (Veltz, 1999:13), in physical sciences, a difficulty to incorporate into the analysis of change on natural landscape the learning of "the social thing" prevails.

In this document we propose the notion of environment-society interface in order to ar-ticulate the explanations that we have separated until today. For that, we examine the theo-retical background of three disciplines -two of physical order and one social-, to define a unified own methodology. Secondly, that methodology is applied to the Central Region. The preliminary outcomes allow to distinguish the areas where urban expansion on rural environment overlaps the most valued environmental areas with great accuracy and order.

We have had an unexpected outcome but which is very important for planning: when urban sprawl is analyzed separate, that is to say, from a socioeconomic point of view, the hinterland of the city-region grasps between 100 and 120 kilometers around Mexico City the main central place- and the principal dynamics is found inside the regional belt. When the physical-environmental factors are introduced, the dynamics of physical-social interrelation goes beyond the belt and goes into the distant peri-urban space. The importance of this outcome relates mainly to the fact that, at the moment, no public policy, neither those related to the urban subject nor those focused on environment, recognizes the geographical extent of this field.

We name the identified areas as contact spaces and they constitute a first necessary step to perform more accurate local studies as well as a way to define specific environmental protection policies.

\section{THEORETICAL BACKGROUND OF THE INTERFACE}

One of most valuable backgrounds to build the interface notion is the outline proposed by Hodge, since it identifies interaction processes or components among environment and society fields (see graphic 1). According to Hodge, interaction between people and ecosystems takes three shapes: reasons for interaction, the undesired effects of those reasons and possible policies to face those problems. In the author's terms, interactions contribute to:

1. to satisfy basic needs and to provide a quality of life, and consequently, they are valued,

2. to impose physical, chemical or biological perturbations on ecosystems,

3. to restore ecosystem and,

4. to reflect the success of advance in goals and targets of policies, regulations or legislations (Hodge, 1996:21).

Namely, interface is the ensemble of specific relationships between one society and the environment which surrounds it, besides a "territory" -though these interrelations are exposed, particularly, in an intermediate territory between both poles- generally fore mentioned as "peri-urban" space. According to Hodge, we can discern from his diagram, some of the components of each "section" the interaction case between urban sprawl (People) and the environment (Ecosystems). Among the first ones we can find notions such as urban expansion, economic specialization, rural industrialization and accessibility, while among the second ones we find such concepts as vegetal coverage, semi natural ecosystems (agricul- 
tural areas), habitats and discharge areas, by only mentioning some of them. The first ones are studied by Regional Geography while the second ones are dispersed in at least two disciplines: Landscape Ecology and Hydrogeology (see table 1).

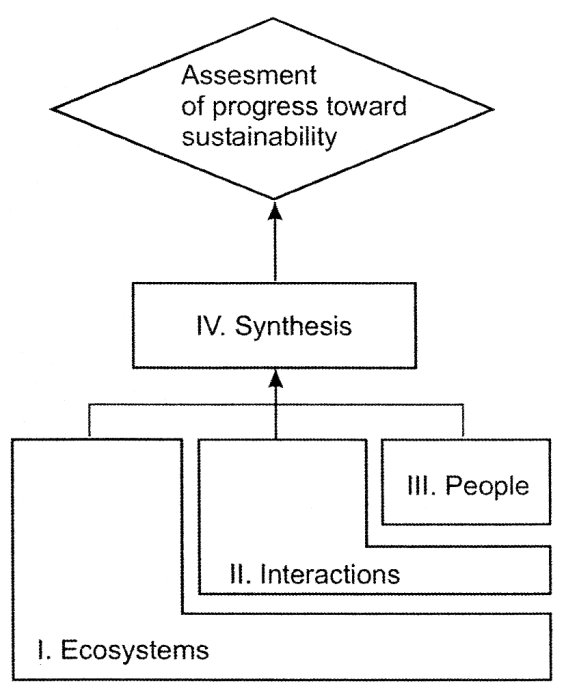

Source: Hodge, 1995

Table 1: General components of environment/society interface

\begin{tabular}{|c|c|c|}
\hline Ecosystems & Environment/society interface & People \\
\hline $\begin{array}{l}\text { - vegetal coverage } \\
\text { - seminatural } \\
\text { ecosystems } \\
\text { (agricultural areas) } \\
\text { - natural habitat } \\
\text { - recharge or discharge } \\
\text { groun water areas } \\
\text { - hydric regime } \\
\text { - biogeochemical } \\
\text { cycles }\end{array}$ & $\begin{array}{l}\text { - Water, food and raw materials' } \\
\text { supply } \\
\text { - waste management and used } \\
\text { waters systems } \\
\text { - conservation areas } \\
\text { - perturbated ecosystems } \\
\text { - rural-urban, urban-urban and } \\
\text { rural-rural migrations } \\
\text { - commuters' movements in } \\
\text { a job basin }\end{array}$ & $\begin{array}{l}\text { - demographic increase } \\
\text { - urban expansion } \\
\text { - economic specialization, PEA } \\
\text { (Economically Active Population) } \\
\text { - rural industrialization } \\
\text { - urban accessibility and mobility }\end{array}$ \\
\hline
\end{tabular}

Source: Authors' own elaboration.

Which seems clear is that concepts like that of sustainability cannot be undertaken only from interpretations of the state of natural system, because they need human judgments and values (Costanza, et al, 1992). Therefore, neither the purely environmental indicators, nor the 
purely social ones are decisive to evaluate advances toward sustainability notion. The interface notion allows to locate ecosystemic processes which are able to temper urbanization's pressures and the urban dynamics they own.

In order to reach that, we count upon a series of notions that undertake different flanks of the interrelation, like water, food and raw materials' supply toward cities, the analysis of waste management and used waters, rural-urban migrations or commuters' movements in a job basin. We are going to follow the complete cycle in the next exercise, from social side (People) toward natural side (Ecosystems), enlightening the corresponding interrelations.

We are going to see each of them individually, and then we will try to "combine" them. The "relational" approach proposed is based on differentiating "non relational" and others "relational" processes. The formers are those concentrated on particular phenomena, without paying attention to their interrelations with components that have been studied by other disciplines but which allow to elaborate analysis that we will call "endogenous" to separate them from the second ones which, while considering interrelations, we will call "relation's".

In the first case, we can suppose that, larger the endogeneity of one element is, smalller is the knowledge of its interrelations. On the opposite side, if the relationality of components is larger, we will be in front of situations that we can name as relational processes or spaces that, independently of relationship characteristics and nature, either profitable or negative, they constitute contact spaces between the "social" and the "environmental".

\section{Processes in Landscape Ecology}

In Landscape Ecology we can distinguish a series of relational components such as those related to natural ressources management and those called environmental goods or services. The idea that landscape structure and sustainable conservation of its integrity depend upon a multiscale perspective, with limits or boundaries that cross each other and an "adaptative" type management, is proposed in this approach. This means that one dynamic conception results necessary in the face of the constant changes that it experiences due to natural transformations as much as anthropic ones (Bastian, 2001, Groot et al, 2002).

These positions give the rule for a new focus in which social aspects such as the geographical concept of region (this concept may coincide with Landscape Ecology principles taken to a regional scale (Odum, 2002:464). But even inside this approach, the treatment of the questions related to water performance is not explicit. That has to be solved with another discipline tools, the Hydrogeology.

\section{Processes in hydrogeology}

Since ground water is a geologic agent of general character, the number and diversity of natural phenomena associated to the operation of underground flow systems is practically limitless (Töth, 2000). For such a reason, the study of basic components (not relational) of hydrogeological context, can be useful to design management strategies which have as objective to maintain human and ecological resource benefits, like sustainable supply and the maintenance of recharge-discharge areas (Sophocleous, 1997, Neufeld, 2000). 
However, it should be recognized that is not enough to design outlines of hydric resources supply, to solve the complex series of problems coming from society-environment interactions. It is necessary to consider other frames of analysis that pay attention to purely social processes. It is here where proposals made from Regional Geography, allow to reach -with emphasis in the social one- to specific interactions of environment-society interface.

\section{Processes in Regional Geography}

Historically, the regional focus has been holistic, including territories and urban societies as much as rural ones. Although the prevailing processes are mostly of metropolitan character, its incidence on regional fields is difficult to frame in a cause-effect relationship, as one makes with physical indicators.

In the case of relationals components such as water supply for urban consumption, periurban agriculture and sewage of used waters, in the current time they reach a considerable magnitude. For example, in a global scale, annual water extraction from its natural medium, is now about 3,600 $\mathrm{Km}^{3}$, when in 1680 was smaller than $100 \mathrm{Km}^{3}$ (Kates, et al, 1990). Equally, urbanization of sites that have environmental value, also arises as a trouble in big European metropolis by the same time.

Only urban sprawl is the most recent process and its pertinence as an analysis category is still studied in less developed countries, like Mexico. Wherever it appears, the intense population and activities relationship between country and town have taken to stump the urban frontier in such a way that is impossible to trace a clear border line, since new relationships between the traditionally established urban components and peri-urban relocation.

Now we propose to resume the three reviewed approaches. The first methodological step consists on identifying such environmental units in the Central Region of Mexico, from a physical point of view in order to integrate it later to the social perspective.

\section{ENVIRONMENTAL UNITS DEFINITION AT CENTRAL REGION}

Although most of the territory of the region presents a humid or semi-humid climate, ground water represents the main source of supply for population, since the majority of surface glides and channels are employed for moving used waters out (CTMMA, 2003). It is for this reason that identification and evaluation of environmental importance areas can be fulfilled from the examination of performance conditions of this geological agent in the region.

Inside the hydrological continuum from recharge areas to discharge areas, an interaction dynamics between ground water and surface water is produced, which conditions a great variety of ecosystemic processes (Töth, 1999, Sophocleous, 2002, Winter, 2001) as soon as they determinate the environmental change magnitude (Edmunds, 1996).

There exists a wide discussion regarding which type of spatially defined units are the proper ones for hydric resource management (Winter, 2001). For Mexico's case the concept of hydrographic basin has dominated regulation and implementation of public policies schemes, although there is a strong dependence on ground resource and in the most of the cases, per- 
formance boundaries of aquiferous systems do not correspond to the superficial border, since the territory is characterized by a complex geological and geomorphologic frame.

Particularly, it has been suggested that the handling outlines based on the hydrographic basin concept and the little knowledge one has about the real performance limits are some of the causes of policies inefficiency facing the environmental complex problematic of the region (Tortajada, 2001; Angeles-Serrano, et al., 2003). For this reason, the delimitation of recharge and discharge areas starting from its likely functional limits in the territory, as much spatially like temporally, is decisive to make a diagnosis of the environment-society interaction processes that serves as a basis for the formulation or modification of plans and programs for resource management.

It exists, however, a strong lack of information to carry out a quantitative evaluation of the recharge process and its interaction with natural discharge environments as humid soils, bodies of water, riparias areas, etc. In this paper, an identification and systematic ponderation was carried out of those components that control the flow of ground water: 1) climate, 2) relief and 3) geological frame (Töth, 1963, Freeze and Witherspoon, 1967, Winter, 2001, Sophocleous, 2002), as well as of those that are surface manifestations of the ground flow: i) soil type and ii) vegetation (Töth, 1999).

When assigning different categories to each one of the components a pondered classification is obtained from each one of them, in accordance with a qualitative evaluation about how are manifested in recharge areas, opposite to what happens in discharge or recharge areas of local flows of little regional interest (see table 3).

On the other hand, urbanization processes, irregular settlements presence, agricultural frontier expansion through natural areas and modification of traditional rural economic activities, can transform ground water recharge and discharge conditions. For this reason, identified environmental units refer basically to those areas that keep a high degree of conservation agreeing with their characteristics of vegetable coverage (Palacio, et al., 2000). What is assumed here, is to concentrate on spaces where regional dynamics of settlement coincides with areas of greater environmental value.

The previous methodological criteria were useful to carry out a first exercise of regional classification of those areas with potential for recharge or discharge of ground water starting from the reclassified sum of the pondered and normalized values of gradients, topography and vegetable coverage byr community, in scale 1:250,000. In the map I the location and relative value of identified environmental units are presented, which were valued by their biggest relative altitude (except glaciers) and smaller slope.

Due to the fact that only areas with a bigger degree of natural vegetation conservation were considered, it is possible to assume that they keep their natural potential for recharge. Therefore, biophysical factors (precipitation, evapotranspiration and infiltration ability of soil and undersoil), are those which control quality and quantity of infiltrated water. On the contrary, in the wide agricultural areas and in those of induced pasture-ground, as well as in urban areas, it is necessary to use a greater number of factors and evaluation criteria to determinate change in quality and amount of recharge water (Custodio, 1997, Carmon and Shamir, 1997).

The vegetation criteria has also been used to delimit discharge areas, as well as the presence of lakes and lagoons or areas without apparent vegetation, which are characteristic of 
areas of regional flows discharge due to its high salinity, as Texcoco Lake (Huizar, et al., 2003). Ground waters flows discharge areas are considered of high environmental value because of the biodiversity they show and its capacity to temper the effect of contamination processes, such as waste infiltration. This is the case of humid soils of Xochimilco and Texcoco located in Mexico City periphery.

Table 2: Identification, Classification anf Hierarchization of areas with environmental value

\begin{tabular}{|c|c|c|}
\hline \multirow{2}{*}{$\begin{array}{c}1 \text { Discharge areas } \\
\text { LOW }\end{array}$} & \multicolumn{2}{|c|}{2 Rechargeareas } \\
\hline & MEDIUM & HIGH \\
\hline it does not apply & Arid and semi-arid & Humid and semi-humid \\
\hline $\begin{array}{l}<1500 \text { mosl (meters over sea level) for } \\
\text { regional flows, a range between } 1500 \text { to } \\
2000 \text { mosl was used in the plateau (Alti- } \\
\text { plano), with gradients larger than } 30^{\circ} .\end{array}$ & $\begin{array}{l}\text { 2000-3000, moderate } \\
\text { gradients: } 15-30^{\circ}\end{array}$ & $\begin{array}{l}>3000 \text {, low gradients } \\
\text { smaller than } 15^{\circ} .\end{array}$ \\
\hline $\begin{array}{l}\text { Lacustrine, alluvial silts of more } \\
\text { relative age. }\end{array}$ & $\begin{array}{l}\text { Alluvial, volcanic silts, of } \\
\text { tertiary era }\end{array}$ & Recent volcanic. \\
\hline $\begin{array}{l}\text { Contacts of the flaws of highly } \\
\text { contrasting permeability } \\
\text { Great thickness of the units and } \\
\text { bigger heterogeneity of the materials. } \\
\text { Older fissures can present salts precipita- } \\
\text { tion that diminish porosity }\end{array}$ & $\begin{array}{l}\text { Bigger heterogeneity or } \\
\text { thickness of material } \\
\text { Fissures and recent frac- } \\
\text { tures of medium magni- } \\
\text { tude }\end{array}$ & $\begin{array}{l}\text { Highly fractured material } \\
\text { Recent fissures of bigger } \\
\text { relative magnitude }\end{array}$ \\
\hline $\begin{array}{l}\text { Humid soil vegetation } \\
\text { Halophilous or Gypsophila } \\
\text { Palmar } \\
\text { Popal-Tular }\end{array}$ & $\begin{array}{l}\text { Mixed Forests, Low for- } \\
\text { est, perennial and subper- } \\
\text { ennial vegetation } \\
\text { Categories of high re- } \\
\text { charge with secondary } \\
\text { vegetation typical of per- } \\
\text { turbed environments }\end{array}$ & $\begin{array}{l}\text { Xerophila vegetation } \\
\text { (heath, chaparral, hui- } \\
\text { zachal), temperate forest } \\
\text { (oyamel fir, pine, tascate), } \\
\text { high and medium forest } \\
\text { sub-perennial, perishable } \\
\text { and sub-perishable }\end{array}$ \\
\hline Basics & \multicolumn{2}{|l|}{ acid, neutral } \\
\hline
\end{tabular}

Note: The classification, although it is general, was made according to biophysical characteristics for Central Region of Mexico, for what they could vary in other regions. A wider discussion about this sort of qualitative valuation can be found in Delgado-Campos and Angeles-Serrano, 2003.

Fuente: Authors' own elaboration based on Töth, 2002.

Finally, to make easy comparison between these areas (that keep their ecosystemic functions) with the complex dynamics of urban sprawl that characterizes the region, a relative value was assigned by municipality, according to the coverage percentage presented by each environmental valued unit. The outcome allows to reclassify municipalities with a relative value of agreement with the percentage of natural recharge areas and discharges of ground water that they own. (see table 3 ). 
Table 3: Reclassification of Areas with environmental value by municipality

\begin{tabular}{|c|c|c|c|c|c|c|c|}
\hline \multirow[b]{3}{*}{ Discharge } & \multicolumn{7}{|c|}{ Extent of recharging environmental units coverage by municipality (\%) } \\
\hline & \multicolumn{2}{|c|}{ Low } & \multicolumn{2}{|c|}{ Medium } & \multicolumn{3}{|c|}{ High } \\
\hline & 0 & $<50 \%$ & $>50 \%$ & $<50 \%$ & $>50 \%$ & $<50 \%+\mathrm{M}$ & $>50 \%+M$ \\
\hline It has not & 0 & 1 & 2 & 2 & 3 & 3 & 4 \\
\hline It does have & 1 & 2 & 3 & 3 & 4 & 4 & 5 \\
\hline
\end{tabular}

Source: Authors' own elaboration.

This reclassification by municipality allows, now, to incorporate the social type variables, particularly those related to urban sprawl ${ }^{2}$.

\section{URBAN SPRAWL DYNAMICS}

The study of urban sprawl is quite recent, as much to world level as in our country. In general terms, it is accepted that it results from three types of sociospatial processes: 1) novel trends related to economic changes with strong impact on territory's conformation (intraregional decentralization and sprawling of typically urban activities, industry, trade and services), 2) social processes among which sub-urbanization, counterurbanization and polarization reversal are outstanding and, finally, iii) as a result of the above-mentioned, integrated urban processes because of the construction of the necessary material supports to carry out the first two groups.

a) Nevertheless, there is no proved methodology to measure urban sprawl ${ }^{3}$. In this paper we propose, besides, to be concentrated only on rural spaces that more express wanted sprawling. The analysis has been carried out in two times:

b) Municipalities were distributed in three groups according to the rural-urban category change observed between 1970 and 1995: i) those that changed from rural to transition, ii) those that changed from transition to urban and iii) those that changed from rural to $u_{\text {rban }}{ }^{4}$.

Former distribution was contrasted with medium index value of four indicators that express socioeconomic changes related to sprawling: a) Migration, as a percentage of population related to inmigration or emigration of inhabitants, b) Urbanization Level, as the proportion of urban population with regard to total population, c) Non Agricultural Labor Force as the percentage of employment in industrial and services activities and d) Rural Industrialization as rural areas that present a quotient of industrial location (Delgado, 2003).

\footnotetext{
${ }^{2}$ A frequent trouble when comparing both types of variables, environmental and social ones, is that societies are often expressed in geostatistical units, such as municipalities, while environmental variables are always geoforms.

${ }^{3}$ A tentative proposal can be seen in Delgado et al., 1999.

${ }^{4}$ We consider as rural those municipalities with a population smaller than 10,000 inhabitants, municipalities in transition, those between 10,000 and 15,000 inhabitants and urban municipalities, those whose population overcomes 15,000 inhabitants.
} 
In this way, the greatest value (5) was assigned to municipalities that have had the most drastic change of category rural-urban and that, at the same time, have had the greatest medium index value. At the inferior extreme, the minor value (0) was assigned to those municipalities that have changed from rural to transition (minor group dynamics) and which have had low values for the index. Intermediate values ( 2 to 4 ) were distributed among intermediate ranks in both sides of the matriz. Obtained values allow to identify those municipalities where there is a high dynamics of rural-urban change (see table 4).

Table 4: Identification of the RURAL-URBAN DYNAMICS

\begin{tabular}{|c|c|c|c|}
\hline \multirow{4}{*}{$\begin{array}{l}\text { RURAL-URBAN } \\
\text { CHANGE } \\
(1970-1995)\end{array}$} & \multicolumn{3}{|c|}{$\begin{array}{c}\text { URBAN SPRAWL } \\
\text { a) Migration } \\
\text { b) Urbanization Level } \\
\text { c) Non Agricultural Labor Force } \\
\text { d) Rural Industrialization }\end{array}$} \\
\hline & \multicolumn{3}{|c|}{$\longrightarrow$} \\
\hline & \multicolumn{3}{|c|}{ Medium index value } \\
\hline & $\begin{array}{l}\text { Low } \\
(0-2)\end{array}$ & $\begin{array}{l}\text { Medium } \\
\text { (3 to 4) }\end{array}$ & $\begin{array}{l}\text { High } \\
\text { (5 to } 6)\end{array}$ \\
\hline 0 Rural to Transition & $\mathbf{0}$ & 2 & 3 \\
\hline 1 Transition to Urban & 1 & 3 & 4 \\
\hline 3 Rural to Urban & 2 & 4 & 5 \\
\hline
\end{tabular}

Source: Authors' own elaboration.

In spatial terms, the obtained outcome throws the following results:

a) Unlike geographical diversity of the particular indicators considered individually (migration, non agricultural labor force and urbanization level), the obtained classification presents most of municipalities with the biggest value of rural-urban change dynamics at the external boundaries of the regional ring, and

b) A spatial overflow of this type of municipalities in the distant peri-urban. The above mentioned seems to confirm, on one hand, the heterogeneity of the regional ring as well as the extent of urban sprawl.

The following methodological step consists on combining the outcomes of both components, from the natural context and from the social one, which constitutes properly, the interface society-environment.Society-environment interaction.

It has been argued that pressure on natural ressources and their management make necessary to undertake environmental and social problems from an interdisciplinary and in great scale perspective, because it is in this way that any sustainable management plan can be successfully implemented.

According to Odum"(...) One way of moving toward regional approach is to describe raw data in a spatially explicit way, or over small spatial scales, in order to have data rapidly 
aggregated in different ways and to create different regions depending on the question of interest (Odum, 2002:464)".

The proposal for final integration is to ponderable hierarchically these contact spaces where there is, in a potential way, an interaction between urban sprawl dynamics and the defined environmental units. The above-mentioned can be achieved overlapping those municipalities that have a larger rural-urban change dynamics with different units that have greater environmental value (see table 5).

Table 5: Identification of Contact Spaces (Rural-Urban Dynamics in municipalities with High Environmental Value)

\begin{tabular}{|c|c|c|c|c|c|c|}
\hline \multirow{2}{*}{} & \multicolumn{6}{|c|}{ Environmental value } \\
\cline { 2 - 7 } & \multicolumn{2}{|c|}{ Discharge Areas* } & \multicolumn{2}{c|}{ Potential Recharge Areas } & \multicolumn{2}{c|}{ Both Areas } \\
\hline $\begin{array}{l}\text { Change of the } \\
\text { Rural-Urban } \\
\text { Dynamics }\end{array}$ & $\begin{array}{c}\text { Non } \\
(0)\end{array}$ & $\begin{array}{c}\text { Yes } \\
(1)\end{array}$ & $\begin{array}{c}\text { Medium } \\
(2)\end{array}$ & $\begin{array}{c}\text { High } \\
(3)\end{array}$ & $\begin{array}{c}\text { Medium } \\
\text { Recharge }+ \\
\text { Discharge (4) }\end{array}$ & $\begin{array}{c}\text { High } \\
\text { Recharge }+ \\
\text { Discharge (5) }\end{array}$ \\
\hline 0 & 1 & 1 & 1 & 2 & 2 & 3 \\
\hline 1 & 1 & 2 & 2 & 2 & 3 & 3 \\
\hline 2 & 1 & 2 & 3 & 3 & 3 & 4 \\
\hline 3 & 2 & 2 & 3 & 4 & 4 & 4 \\
\hline 4 & 2 & 3 & 3 & 4 & 5 & 5 \\
\hline 5 & 3 & 3 & 4 & 4 & 5 & 6 \\
\hline
\end{tabular}

* Municipalities with presence of discharge areas Source: Authors' own elaboration.

The outcome expresses hierarchically the territories where urban sprawl processes pressure threats the integrity of defined environmental units. 36 municipalities have been identified with high or very high potential of interaction between rural-urban change dynamics and the greatest environmental value areas as ground water recharge and discharge areas. Most of them are located inside the regional ring, nevertheless, they can also be found in distant peri-urban limits, beyond the ring (see Table 6).

If municipalities with medium value are also considered (129 or 23\% of municipalities), their location allow to identify at least five big clusters if contact spaces, where changes on land use can have negative effects over natural contiguous areas, which are characteristic of urban basins: decrease of recharge because of the expansion of urban border, contamination due to industrial and domestic waste, instability of hillsides due to enlargement of highway net, soil salinity, eutrophication of water bodies and land sinkings, among others.

Nevertheless, these contact spaces can constitute a positive interaction with the natural environment if resource management and protection schemes are orchestrated or if the traditionally "rural" activities combine themselves with new eco-tourism and environmental education activities that depend on the maintenance of the resource for their realization. 
Table 6: Contact Spaces Reclassification.

\begin{tabular}{|c|c|c|c|c|c|c|c|c|}
\hline \multirow{2}{*}{$\begin{array}{c}\text { Rural-Urban } \\
\text { Dynamic }\end{array}$} & \multicolumn{6}{|c|}{ Enviromental Units Value } & \multicolumn{2}{|c|}{ Total } \\
\hline & 0 & 1 & 2 & 3 & 4 & 5 & Population L & lities \\
\hline Population & & 13.745 & 184.551 & 10.009 & 122.395 & & & \\
\hline 0 Localities & & 26 & 595 & 8 & 269 & & 330.700 & 898 \\
\hline average Migration & & 99,0 & 66,3 & 10,7 & 91,5 & & & \\
\hline Population & & 16.331 & 211.185 & & 227.659 & 16.557 & & \\
\hline 1 Localidades & & 106 & 581 & & 666 & 140 & 471.732 & 1.493 \\
\hline average Migration & & $-13,8$ & 65,5 & & 109,7 & 12,5 & & \\
\hline Population & 14.483 & 41.094 & 249.924 & 15.086 & 182.033 & 15.184 & & \\
\hline 2 Localidades & 6 & 136 & 528 & 23 & 327 & 67 & 517.804 & 1.087 \\
\hline average Migration & 130,1 & 94,1 & 100,6 & 337,4 & 111,1 & 218,3 & & \\
\hline Population & 47.398 & 59.282 & 430.621 & & 201.623 & & & \\
\hline 3 Localidades & 61 & 231 & 861 & & 642 & & 738.924 & 1.795 \\
\hline average Migration & 71,8 & 74,7 & 103,9 & & 83,4 & & & \\
\hline Population & 175.130 & 307.507 & 367.549 & & 338.555 & & & \\
\hline 4 Localidades & 76 & 234 & 462 & & 177 & & 1.188 .741 & 949 \\
\hline average Migration & 190,1 & 275,3 & 171,1 & & 160,2 & & & \\
\hline Population & 863.363 & 70.013 & 504.696 & & 21.571 & & & \\
\hline 5 Localidades & 57 & 57 & 421 & & 26 & & 1.459 .643 & 561 \\
\hline average Migration & 148,0 & 284,8 & 193,7 & & 327,6 & & & \\
\hline Total Poblacion & 1.100 .374 & 507.972 & 1.948 .526 & 25.095 & 1.093 .836 & 31.741 & 4.707 .544 & 6.783 \\
\hline Localidades & 200 & 790 & 3.448 & 31 & 2.107 & 207 & & \\
\hline
\end{tabular}

\section{CONCLUSIONS}

Exercise's outcomes allow to identify a wide group of contact spaces which combine an important rural-urban change dynamics (which is part of the most general processes of urban sprawl) to the presence of high environmental value areas in vast periurban spaces of the region. This particular case is one of the environment-society interface examples.

Environmental importance of these contact spaces resides on the fact that they work as ground water recharge and discharge areas that keep relatively well conserved their vegetal coverage and, consequently, their capacity to assimilate waste, habitat provision and attenuation of pollutants. For this reason one can affirm that contact spaces, more than impact areas, may be considered as areas of environmental reduction since they still keep their natu- 
ral performance ability, contrary to what happens in population concentration areas, where impacts are often irreversible.

An unsettled task is to evaluate the historical behavior of ground water resource. There is a consensus with regard to the negative effects of current model of urban supply from distant sources, as well as of used water sewage system that impacts on rural areas at great distances. If the capacity of certain territories to keep ecological and human benefits from ground water diminishes, one must wait the appearance of local problems such as shortage of the resource and pauperization of material conditions of life and conflicts due to competition for having the resource, conditions that, generally, use to generate strong migratory flows rural-urban, urban-urban and rural-rural looking for better life conditions. The above mentioned could impact in a greater extension and complexity of the identified contact spaces.

The above-mentioned puts on relief the need to have a regional planning system that faces urban trends toward concentration, even regional. The development of protection strategies in recharge and discharge areas of ground water should have a high-priority character.

A feasible goal to be reached in the medium and short term is to evaluate contact spaces of the region where basic conditions of regional performance of the aquiferous system are condensed with the perspective of replacing the current system of distant water supply due to its negative effects on the ecosystem.

\section{Bibliografia}

Angeles-Serrano, G., Carrillo-Rivera, J. J., Hernandez G., 2003: Groundwater recharge processes in the Central Region of Mexico, to be published in RMZ-Materials and Geoenvironment: Vol. 50, No. 3.

Bastian 0, 2001: Landscape Ecology - towards a unified discipline? Landscape Ecology 16: 757-766

Centro del Tercer Mundo para el Manejo del Agua, A C, 2003: El recurso hidrico en Mexico, analisis de la situacion actual y perspectivas futuras. The Nippon Foundation Miguel Angel Porrua, Mexico. 269p.

Chilton, et al (eds) 1997: Groundwater in the urban environment, problems, processes and management. Vol. 1. Balkema, Holanda, 682 pp.

Delgado, J., 2003: "Rural Urban Transition and Urban Sprawl, in Proceedings de la reunión annual de la Comision Urbana, International Geographic Union, Pretoria Conference, Perspective on Urban Spheres, Sudafrica (en prensa)

Delgado, J., A. Larralde y C. Anzaldo 1999: "La corona regional de la Ciudad de Mexico. Primer anillo exterior en formacion", en Delgado y B. Ramirez (Coords.), Territorio y cultura en la Ciudad de Mexico, tomo 1, Transiciones, UAM, Plaza y Valdes Editores, Mexico. pp.

Delgado-Campos, J. y Angeles-Serrano, G., 2003: "Espacios de Contacto: Aproximaciones a la interfase naturaleza y sociedad en la Region Centro de Mexico", en proceso.

Edmunds, W., M. 1996: Indicators in the groundwater environment of rapid environmental change, en Geoindicators (assessing rapid environmental changes in earth systems), Gerger, A., y lams, W (eds), Balkema, Holanda, 135-150. 
Freeze, R. A. and Witherspoon, P. A., 1967: Theoretical Analysis of Regional Groundwater Flow; 2. The Effect of Water-Table Configuration and Subsurface Permeability Variation, Water Resources Research 3:623-634.

Garreau, J., 1991: Edge City Life on the new frontier, Anchor Books, Nueva York.

Groot, R., S., Wilson, M., A., Boumans, R., M., 2002: A typology for the classification, description and valuation of ecosystem functions, goods and services, Ecological Economics 41: 393-408.

Head, L., 2000: "Contingent constructions: cultural landscapes and environmental change", en Cultural Landscapes and Environmental Change, Oxford University Press. Serie: Key issues in environmental change. Matthews, J. A., Bradley, R. S., Roberts, N., and Williams, M. A. (Eds). 179p.

Hodge, R. A., 1996: Indicators and their role in assessing progress toward sustainability, en Geoindicators (assessing rapid environmental changes in earth systems), Gerger, A., y lams, W (eds), Balkema, Holanda, 19-24.

Kates, R. W., Turner, B. L., Clark, W. C., 1990: "The Great Transformation", in: The Earth as transformed by human action, global and regional changes in the biosphere over the past 300 years. Turner B. L. .11, et al, (Eds). Cambridge, London.

Neufeld, D. A., 2000: An ecosystem approach to planning for groundwater: The case of Wa-terloo Region, Ontario, Canada. Hydrogeol. J. 8:239-250.

Odum, P., E. () Landscape ecology of the future: A regional interface of ecology and socioeconomics, in: Integrating Landscape Ecology into Natural Resource Management, Liu, J., Y Taylor W.,W., (Eds). Cambridge, UK.

Palacio, J.L., et al, 2000: La condicion actual de los recursos forestales en Mexico: resultados del inventario forestal nacional 2000, Investigaciones Geograficas, Boletin del Instituto de Geografia, UNAM, 43:183-203.

Shiklomanov, I.A., 1993: World fresh water resources, en Gleick P. (Ed) Water in crisis: a guide to the world's fresh water resources, Oxford (UK): Oxford Univ. Press. Pp 13-24.

Sophocleous, M, 2002: Interactions between groundwater and surface water: the state of the science, Hydrogeology J. 10:52-67.

Sophocleous, M. A., 1997: Managing water resources systems: why safe yield is not sustainable. Ground Water 35(4):561.

Tortajada, C., 2001: Capacity Building for the water sector in Mexico an analysis of recent efforts. Water International, IWRA, Vol 26:4, 490-498.

Töth, J., 2000: Las aguas subterraneas como agente geolbgico, causas procesos y manifestaciones. Boletin Geologico y Minero. Vol. 111(4):9-26.

Töth, J., 1963: A Theoretical Analysis of Groundwater Flow In Small Drainage Basins, Journal of Geophysical Res, 68:4795-4812.

Veltz, P., 1999: Mundializacion, ciudades y territorios, Editorial Ariel, Espana, 254p.

Winter, T., 2001: The concept of hydrololgic landscapes, Journal of the American Water Resources Association, 37(2):335-349. 